\title{
Water security and climate change
}

Rachel Cooper \& Roz Price

GSDRC, University of Birmingham \& Institute of Development Studies

19 July 2021

\section{Question}

Provide an overview of the relationship between water security and climate change, including impacts and options for mitigation and adaptation.

\section{Contents}
1. Summary
2. Global water crisis and climate change
3. Climate resilience through water
4. Transformational change
5. References

The K4D helpdesk service provides brief summaries of current research, evidence, and lessons learned. Helpdesk reports are not rigorous or systematic reviews; they are intended to provide an introduction to the most important evidence related to a research question. They draw on a rapid deskbased review of published literature and consultation with subject specialists. other Government departments, but the views and opinions expressed do not necessarily reflect those of FCDO, the UK Government, K4D or any other contributing organisation. For further information, please contact helpdesk@k4d.info. 


\section{Summary}

Attention is coalescing around water and climate change, and the agendas for water security ${ }^{1}$ and climate action are converging. There is growing appreciation of water as a crosscutting mechanism for improving the effectiveness of global and national climate change policies (Smith et al., 2019). Water has long been recognised as a central component of climate change impacts as well as being an important consideration in mitigation and effective adaptation - where it can be both an enabling factor and a limiting factor (UN-Water, 2019). However, the connections go beyond just recognising the importance of water for climate change or simply making the "water sector" climate resilient; there is a need for system-wide coherence on water across different national and international agendas and transformational change of water management (UNESCO, UN-Water, 2020). The water crisis and the climate crisis require urgent action, and call for sustained and integrated support, leveraging complementary resources, with enhanced coordination in the context of growing uncertainties. As countries review and implement their Nationally Determined Contributions (NDCs) as part of the Paris Agreement, there is a unique opportunity to improve and enhance water management practices to increase climate resilience, improve ecosystems and reduce the risk of water-related disasters (UN-Water, 2019). ${ }^{2}$

\section{Global water crisis and climate change}

\section{The global water crisis}

Water is vital for human health and wellbeing, economic production and sustainable development (food security, energy production, ecosystems etc.), and many of the Sustainable Development Goals (SDGs) are water-dependent (Smith et al., 2019; UN-Water, 2019). Water is both the 'water sector' (i.e. water supply, storage and sanitation) and profoundly cross-sectoral, and needs to be approached as such (Smith et al., 2019: 2). Nexuses exist between water and economic sectors including energy, food and urban systems (Roidt \& Avellán, 2019). Consequently, water should be understood as an interlinked resource, managed across economies, from local to national and higher levels (Smith et al., 2019). It is hence important to improve overall water resilience due to cascading effects water competition can have on people, economies and natural systems (UN-Water, 2019).

Water resources are under pressure in many regions with multiple complex drivers generating an increasing demand for water, or a decreasing supply in some areas ${ }^{3}$ (UNESCO, UN-WATER, 2020). Drivers include population growth, migration, economic

\footnotetext{
${ }^{1}$ UN-Water defines water security as "the capacity of a population to safeguard sustainable access to adequate quantities of acceptable quality water for sustaining livelihoods, human well-being, and socio-economic development, for ensuring protection against water-borne pollution and water-related disasters, and for preserving ecosystems in a climate of peace and political stability" (UNESCO, UN-Water, 2020: 33).

2 This rapid review draws on an array of key, recent academic and non-academic resources. The evidence base around water and climate change is extensive and growing - this review only provides a snapshot.

3 The International Water Management Institute (IWMI) provides many tools and digital data to explore water resources, flood risks and drought (see https://www.iwmi.cgiar.org/resources/data-and-tools/). Specifically, IWMI and IHE-Delft have developed Water Accounting-plus (https://www.wateraccounting.org/) which integrates satellite data, modelling and ground-based measurements to generate spatially-distributed information on water flows, stocks, consumption, and services from complex river basins, and how these change over time.
} 
development, urbanisation, shifting consumption patterns, land-use change, environmental degradation, biodiversity loss and climate change (UN-Water, 2019: 7). These drivers are fuelling: rising water demands for food, energy, domestic consumption and lifestyle; increased competition for water between sectors; and degraded water quality (the 'invisible' water crisis). This will lead to more difficult trade-offs, especially in areas already facing water stress (UN-Water, 2019).

Water scarcity is projected to increase and could lead to heightened competition between different users and uses, and across political boundaries (Timboe et al., 2020). ${ }^{4}$ Global water use has increased by a factor of six over the past 100 years and continues to grow steadily at a rate of about $1 \%$ per year (UNESCO, UN-WATER, 2020). Current estimates suggest that 3.6-4 billion people live in areas with severe water scarcity for one month per year (Mekonnen \& Hoekstra, 2016; UN-Water, 2019). This is projected to increase to an estimated 4.8-5.7 billion people by 2050 (UN-Water, 2019). There is emerging evidence that water stress, scarcity, drought, and slow and sudden onset water-related disasters are a factor in migration decisions, as well as being a risk multiplier for conflict and instability (UN-Water, 2019; Cooper, 2021). The World Economic Forum (WEF), for example, has long regarded water crises $^{5}$ as one of the top global risks based on both severity and likelihood (WEF, 2021: 14).

\section{The climate crisis is a water crisis}

Water and climate change are inextricably interlinked, and the linkages are complex and multidimensional (Kerres et al., 2020). Climate change manifests itself primarily through changes in the global water cycle, increasing variability in water availability, water stress and scarcity and affecting water quality. Furthermore, current water and sanitation systems are high-carbon, lowresilience, contributing about 10\% of global greenhouse gas emissions per year (GIZ, 2020 cited in UN Climate Action, 2020: 8).

Water is also the medium through which societies, economies and ecosystems will primarily experience climate change (UN-Water, 2019; Global Water Partnership (GWP), 2019):

- Increased frequency and intensity of extreme events: including tropical storms, floods, droughts, and cyclones amongst others. UN-Water (2019) estimates $90 \%$ of natural disasters over the last decade were water-related. Floods and droughts are both likely to increase. Whilst impacts will vary by region, human exposure to flooding due to more frequent heavy rainfall will increase and flood risks will expand as warming increases (Smith et al., 2019; UN-Water, 2019). Both drought related to less rainfall and less soil moisture (agricultural drought) are projected to increase in frequency in dry regions. There may also be increased frequency of short or flash hydrological drought (Smith et al.,2019; UN-Water, 2020). Groundwater recharge is also likely to be reduced due to increasing frequency and intensity of droughts.

- Increased water variability and availability: including changes in rainfall patterns (including seasonal patterns, onset and length), heat waves and extreme cold affecting changes in runoff to rivers, lakes and wetlands and melting ice and reduced snow cover

\footnotetext{
${ }^{4}$ See for example the Aqueduct database and tools, which help to identify and evaluate water risks (such as floods, droughts and stress) around the world - https://www.wri.org/aqueduct [accessed 12/07/2021]

5 In the WEF's Global Risks Report 2021, previous risks considered to be different manifestations of the same risk were merged, including "food crisis" and "water crisis" combined into "natural resource crises" (WEF, 2021).
} 
(Smith et al., 2019: 4). Loss of glacial storage is estimated to reduce summer base-flow and groundwater recharge. Reduced river run-off is likely in arid and semi-arid areas, leading to reduced water availability by mid-century (Smith et al., 2019). Many drylands, already vulnerable as a result of limited rainfall, are expected to receive less or more variable rainfall due to climate change (UNESCO, UN-Water, 2020).

- Water scarcity: climate change will aggravate the situation in areas that are currently water stressed and also generate water stress in regions where water resources are currently abundant. Both surface and groundwater sources will be affected. The area of land subject to increasing water stress is projected to more than double by 2050 (Smith et al., 2019). Physical water scarcity is often a seasonal phenomenon, rather than a chronic one, and climate change is likely to cause shifts in seasonal water availability throughout the year in several places (UNESCO, UN-Water, 2020). It is projected that limiting global warming to $1.5^{\circ} \mathrm{C}$ above pre-industrial levels compared to $2^{\circ} \mathrm{C}$ could reduce the proportion of the world's population exposed to an increase in water stress induced by climate change by up to $50 \%$ (UN-Water, 2019).

- Water quality: will be affected by a number of factors including: increased temperatures increasing organic matter, nitrate and phosphorus levels in river water; reduced dissolved oxygen (reducing the self-purifying capacity of freshwater bodies); increased sediment, nutrient, and pollutant loadings from heavy rainfall; increased concentration of pollutants during droughts; disruption of treatment facilities during floods; and increased coastal erosion and contamination of surface and groundwater through saline intrusion as a consequence of sea level rise (UNESCO, UN-Water, 2020). Small island developing states are particularly vulnerable to accelerated sea level rise and its consequences.

Despite the growing evidence that the changing climate will affect the availability and distribution of water resources, some uncertainties remain, especially at local and basin scales (UNESCO, UN-Water, 2020). There is general consensus about temperature changes, however, there is more variability and ambiguity in projected precipitation trends. Often, trends in extremes (heavier precipitation, heat, prolonged droughts) show a clearer direction than trends in annual precipitation totals and seasonal patterns (UNESCO, UN-Water, 2020). To add to the uncertainty and scale of the problem, different regions have different underlying vulnerabilities. Strong interactions among multiple drivers combined with the intrinsic complexity of hydrological processes and systems make it difficult to precisely assess the full cascade of possible water system changes and their causalities. This uncertainty calls for alternative, risk-based water management approaches for a range of plausible future conditions (UN-Water, 2019: 12).

\section{People will experience climate change through water}

Water-related climate impacts are already being experienced. They pose risks to many sectors where access to a reliable water supply is critical, including the energy, agriculture, sanitation, health and transport sectors (UN-Water, 2019; Timboe et al., 2020). Water-related impacts could also have spill-over effects on the stability of social and political systems. Whilst the evidence base does not suggest a direct causal link between water crises and conflict, migration or fragility, water can potentially act as a destabilising force and risk multiplier (in combination with many other factors) (Smith et al., 2019; Cooper, 2021). There is also growing awareness of the financial implications of the water-related impacts of climate change. For example, companies, investors, cities, and regions have begun to disclose their climate related risks through mechanisms such as 
the CDP (CDP, 2018).

Water-related climate change impacts on different aspects of development include:

- Economic growth and production: water-related losses in agriculture, health, income and property could affect economic growth (UNESCO, UN-Water, 2020). Annual flood damage to property globally is currently estimated at USD 120 billion (Smith et al., 2019). Floods and flood damage may also have economy-wide and indirect damages including supply chain disruption and loss of investor confidence. The economic impacts of drought are harder to define (Smith et al., 2019). Meanwhile water-related physical risks such as changing availability and declining quality could disrupt companies' operations (including energy production) by increasing operating costs, reducing or disrupting production, affecting the supply of raw materials and damaging facilities and equipment (CDP, 2018).

- Health: climate change is likely to slow or undermine progress on access to safely managed water and sanitation through increasing water scarcity and variability, and by extension, affect progress on the elimination and control of water- and sanitation-related disease (UNESCO, UN-Water, 2020). Poorer households may be disproportionately affected as they already lack adequate sanitation and safe water supplies. Climate change will increase incidences of diarrhoea and other waterborne diseases, causing healthcare costs and days lost at work or school. Potential increase in undernutrition due to these diseases or food shortages due to floods and droughts.

- Ecosystems: climate-induced changes to the water cycle and the natural flow regime of rivers can result in cascading impacts throughout entire ecosystems (with primary (direct) and secondary and tertiary (indirect) responses) (UN-Water, 2019). This will impact the provision of water-related ecosystem services, such as water purification, carbon capture and storage, and natural flood protection, as well as the provision of water for agriculture, fisheries and recreation (UNESCO, UN-Water, 2020). Our ability to predict future ecosystem states with confidence is extremely limited (Matthews et al., 2019).

- Settlements: impacts of climate change on urban water systems include both higher temperatures, reduced precipitation and more severe drought, and increasing heavy precipitation and flooding events, making urban planning and the provision of infrastructure difficult. The infrastructure for water and sanitation delivery can also be disrupted. In cases where water supplies rely on distant watersheds, planning needs to look beyond the city's boundaries and consider the long-term impacts of urban expansion on distant freshwater ecosystems and communities (UNESCO, UN-Water, 2020).

The poorest, women and girls, and the most vulnerable (including people with disabilities, elderly people, Indigenous peoples, members of minority groups, and other intersecting inequalities) will be disproportionately affected (UN-Water, 2019). How people experience climate change depends on wealth, social status, and other issues affecting their ability and capacity to adapt, including education, water infrastructure, health services and governance structures (Smith et al., 2019). Poor households often rely on climate and water dependent livelihoods and sectors such as rainfed agriculture, livestock and fisheries, whilst often being more exposed to the impacts of droughts and floods. Poor households also tend to lose a higher share of their assets due to storms or floods (UNESCO, UN-Water, 2020). Climate change will exacerbate women's and girls' unequal access to water, sanitation and hygiene and water for livelihoods, threatening their health, education and well-being. For example, during drought women and girls take longer collecting water from more distant sources, putting girls' education at risk due 
to reduced school attendance (UNESCO, UN-Water, 2020).

\section{Climate resilience through water}

\section{Essential and interlinked role}

Water is essential to achieving the 2030 Agenda for Sustainable Development, the Paris Agreement on Climate Change and the Sendai Framework for Disaster Risk Reduction (GWP, 2019; UNESCO, UN-Water, 2020). Climate-resilient water management could act as a common point of interlinkage to build coherence between these agreements (Smith et al., 2019). Although water is not mentioned explicitly in the Paris Agreement, it is identified within most interim NDCs as the number one priority for adaptation and is directly or indirectly related to all other priority areas (as well as in most National Adaptation Plans (NAPs)) (GWP, 2018; Timboe et al., 2019; Kerres et al., 2020; UNESCO, UN-Water, 2020).

There are concerns with how water is represented in NDCs and NAPs. Typically, water in NDCs and NAPs is mentioned as a source of climate risk (e.g., floods, droughts) or as a "sector" requiring specific interventions. A recent analysis explores how national governments refer to climate-related security risks in their updated NDCs (Remling \& Causevic 2021). They found that water security, often in relation to agriculture, is discussed in 7 of the 16 updated NDCs reviewed, making it the second most prominent concern after food security. Other common themes in the updated NDCs around water security are access to clean and reliable drinking water, and water for ecosystems (Remling \& Causevic 2021: 10). However, current mitigation strategies in NAPs and NDCs largely fail to acknowledge their implicit water commitments, or the need for crosssectoral water integration within strategies (Timboe et al., 2020: 6; UN-Water, 2019). Moreover, water is very rarely described as a resource that connects sectors or acknowledged as itself being vulnerable to climate change impacts (e.g. changes to water quality and scarcity), and few mention water resilience (GWP, 2019). Governance mechanisms and methods for integrating climate and water are largely absent (UN-Water, 2019).

\section{Water's importance in adaptation and mitigation}

Climate resilience, adaptation and mitigation options can have co-benefits, synergies and trade-offs with water security, while failure to consider the role of water in all mitigation and adaptation activities can reduce the effectiveness of these activities and increase the risk of maladaptation or outright failure (UN-Water, 2019).

- The cross-cutting nature of water means the connections are complex and multifaceted - where adaptation and mitigation actions by one sector can directly influence its water demand, which in turn can augment or reduce water availability for other sectors (UNESCO, UN-Water, 2020). This has been steadily recognised over the last decade, however, water is still largely perceived and managed as a stand-alone sector in many countries.

- Water can be both an enabling factor and a limiting factor in our ability to mitigate and adapt to climate change (UN-Water, 2019; UNESCO, UN-Water, 2020). Mitigation measures in particular (such as water reuse, conservation agriculture and renewable energies) have direct implications for water resource use and management (as they often rely on a stable supply of adequate water), whilst water extraction and management 
measures have an impact on carbon emissions due to the energy intensity of water treatment and distribution systems (UN-Water, 2019). It is important to recognise this twoway relationship when developing and evaluating mitigation options (UNESCO, UN-Water, 2020; UN-Water, 2019).

- Water is a connector for climate change adaptation linking impacts felt across sectors, for all social groups; reliable, clean water resources are essential in absorbing and adapting to the changes brought about by climate change (UN-Water, 2019; Smith et al., 2019). Accelerating climate change adaptation and mitigation through water-related solutions benefits water resources management and improves the provision of water supply and sanitation services. It directly contributes to combating both the causes and impacts of climate change, including through Disaster Risk Reduction (DRR).

Key areas of focus according to the Climate Action Pathway on Water are (1) adequate protection of water resources, freshwater ecosystems and people; (2) a water use revolution in the production of food and energy and the water infrastructure required; and (3) a paradigm shift in the reuse of water and wastewater (UN Climate Change, 2020: 3).

Effective adaptation will involve understanding and managing systemic chains of cause and effect, cross-sectoral solutions and synergies in between sectors (Smith et al., 2019). Improving robustness and flexibility of water infrastructure and water management systems blending grey, blue and green infrastructure, building more flexibility into institutions and adopting bottom-up, local approaches will be key (UN-Water, 2019; Matthews et al., 2019). Other key areas to consider include: DRR; joint/co-management of (transboundary) surface and ground- water; integrating the needs of vulnerable groups (e.g. through rights based approaches); integrating urban planning, expanding insurance programmes, expanding use of early warning systems and community engagement; source water protection and sustainable ecosystem management (e.g. ecosystem-based adaptation, nature-based solutions); improved agricultural practices (Matthews et al., 2019; Smith et al., 2019; UN-Water, 2019).

Looking at the connections between water and greenhouse gas emissions, some key areas to consider in relation to water and mitigation of greenhouse gas emissions include: water supply and sanitation; climate-smart agriculture; forestry; nature based solutions; restoration and management of freshwater ecosystems; and the energy sector (such as biofuels and hydropower) (Timboe et al., 2020). Key strategies to tackle greenhouse gas emissions in the water sector include: demand reduction (through efficiency improvements, changing habits etc.); catchment management in conjunction with farmers, landowners, forestry etc.; improving amount wastewater treatment; operational efficiencies; low energy solutions and new technologies; curbing construction (Kerres et al., 2020).

\section{Political economy of water governance}

Addressing climate change offers ways to acknowledge and account for water's inherently cross-sectoral nature; an integrated approach to water is key to maximise synergies (UNWater, 2019; GWP, 2019). This includes transforming governance systems (merging top-down and bottom-up approaches and decision making), management approaches, infrastructure decisions and financing mechanisms (UN-Water, 2019). It is essential that any approaches take into account potentially negative impacts on water resources, the human rights to water and sanitation, and the environment (UNESCO, UN-Water, 2020). Which users and sectors benefit, 
whose knowledge counts in decision-making, and whose priorities prevail are all political. It is hence important to remember that water governance and decision-making are not simply technical matters, but shaped by political economy and how power is used to achieve particular outcomes (Smith et al., 2019).

\section{Uncertainties, robustness and flexibility}

Climate change means old assumptions about a stable climate, assumptions which were used in conventional water planning and management, are being replaced by dynamic and changing climatic uncertainty (Smith et al., 2019; Timboe et al., 2020). New policies and approaches, moving away from long-standing water management practices based on stationarity ${ }^{6}$, towards systematic integration of climate resilience into water decision-making are needed (Timboe et al., 2020). Water managers should also recognise that water infrastructure built now will effectively lock in our choices for decades or centuries whilst the climate continues to change (Smith et al., 2019; Matthews et al., 2019).

In the past decade, a new generation of uncertainty-tolerant approaches have emerged to confidently diagnose risk and to prepare for a range of possible futures in water-related planning and investment (Smith et al., 2019):

- Robustness (solutions perform well across a range of possible futures) and flexibility (solutions retain the ability to respond to unexpected climate shocks and stressors and long-term uncertainties in future climate change impacts) are the best strategies to address the cross-sectoral nature of water and the deep uncertainties of future climate change impacts and water uses (Timboe et al., 2020; Smith et al., 2019; Matthews et al., 2019). Designing robust solutions involves using bottom-up risk approaches, examining systemic intrinsic risks (Matthews et al., 2019). Building flexibility into systems will require alternative methodologies including adaptation pathways and real-options analysis to avoid path dependency (Matthews et al., 2019). ${ }^{7}$ Robustness and flexibility can be applied to all aspects of water resources and water-relevant decision-making and planning, and across all sectors, helping to avoid traps that limit future choices (Smith et al., 2019; Timboe et al., 2020).

- Resilient water management is an emerging integrated approach that builds on concepts such as Integrated Water Resources Management (IWRM) and the water-food-energy nexus (GCF, 2019). It accepts the need for putting in place levers and tools for adapting a complex system to a dynamically changing future, rather than a single fix for a static problem (Smith et al., 2019: 3; Kerres et al., 2019).

- In responding to the deep uncertainty that future climate change brings, Matthews (2020) suggests that as well as robust and flexible decision-making, we look to deep resilience defined as "developing more durable, resilient solutions by expanding the scope of problems being addressed in order to create reinforcing, interlocking, and synergistic

\footnotetext{
${ }^{6}$ For the past two centuries "the basic premise for managing water variability has been the assumption of stationarity - that we can understand future weather patterns and water risks by analyzing trends and patterns from past decades and centuries, ...[i.e.] the past is assumed to predict the future" (Smith et al., 2019: 8).

7 See Tables 1, 2 and 3 in Appendix 2 in Matthews et al. (2019: 50-56) for examples of Flexible, Robust and LowRegret approaches to water management, respectively.
} 
solution sets". This would connect complex, interlocking issues and institutions such as responses to Covid-19, ecosystem restoration, extreme weather events, poverty alleviation, and quality of life issues into a common framework. Deep resilience calls for lumping not splitting of problems, helping identify and account for cross-sectoral impacts and trade-offs between sectors.

\section{Transformational change}

Delivering a water secure, climate-resilient future requires changes to our relationship with nature, changes to the financial system, business models and practices, political will, and increased accountability amongst other integral aspects (CDP, 2018). Due to the complexity of climate stressors and solutions, no single entity, actor or decision maker can "fix" a particular system or embody lasting institutional change in isolation; resilience and adaptation must become normalised across sectors and institutions, with an integrated approach to climate change and water management (Matthews et al., 2019; UN-Water, 2019).

An equitable, participatory, multi-stakeholder approach to water governance in the context of climate change is critical, while sectoral fragmentation and bureaucratic competition could pose serious challenges (UNESCO, UN-Water, 2020). Inclusive governance and involvement of stakeholders, with a focus on gender equality, support to women's participation in decision-making and indigenous knowledge, is broadly recognised as being key to successful climate action and water security measures (GWP, 2019). Greater public participation to discuss and manage climate risk; building of adaptive capacities at multiple levels; avoiding institutional traps; and prioritising risk reduction for socially vulnerable groups are all key areas for transformational change (UNESCO, UN-Water, 2020).

Identified key levers of change include (UN Climate Action, 2020: 4):8

- $\quad$ better information for decision-making; developing stronger political will, with policy and regulation at local, national and international levels to protect water resources and freshwater ecosystems and manage water wisely;

- improved financial flows, with finance and investor communities as catalysts of systemic change to spur development, scaling and uptake of critical technologies, policies and practices;

- shifting of demand from industry, agriculture and domestic consumers towards regenerative and restorative approaches.

\footnotetext{
8 Some of these came out of an event in May 2021 launching the Water Track workstream of the Adaptation Action Coalition. The Coalition was formed in January 2021 and builds on the 2019 UN Climate Action Summit 'Call for Action on Adaptation and Resilience'. It aims to build momentum and support action to adapt and build resilience to the impacts of climate change. A new Water Tracker will also be launched as a tool to help countries strengthen "water resilience" in their national climate planning, helping to highlight gaps and opportunities. See https://www.gov.uk/government/publications/adaptation-action-coalition-an-overview [accessed 12/07/2021]
} 


\section{References}

CDP. (2018). Treading Water: Corporate Responses to Rising Water Challenges. CDP. https://www.cdp.net/en/research/global-reports/global-water-report-2018

Cooper, R. (2021). Water, climate change, and conflict. K4D Helpdesk Report 895. Brighton, UK: Institute of Development Studies. [No link currently available]

GWP. (2019). Addressing Water in National Adaptation Plans: Water Supplement to the UNFCCC NAP Technical Guidelines, 2nd Edition. Stockholm, Sweden: GWP. https://www.gwp.org/globalassets/global/gwp_nap_water_supplement.pdf

Kerres, M., Servos, M., Kramer, A., Hattermann, F., Tänzler, D., Pilz, T., \& Mueller, A. (2020). Stop Floating, Start Swimming. Water and climate change - interlinkages and prospects for future action. Bonn/Eschborn, Germany: Deutsche Gesellschaft für Internationale Zusammenarbeit (GIZ). https://www.everydropcounts.org/imglib/pdf/Water\%20Climate\%20Report\%202020.pdf

Matthews, J., Matthews, N., Simmons, E., \& Vigerstol, K. (2019). Wellspring: Source Water Resilience and Climate Adaptation. Arlington, VA: The Nature Conservancy. https://www.nature.org/content/dam/tnc/nature/en/documents/Wellspring_FULL_Report_ 2019.pdf

Matthews, J. (2020, 2 December). A Proposal for "Deep Resilience": Responding to the Crisis of Deep Uncertainty, AGWA Newsletter Essay. https://www.alliance4water.org/blog-posts/aproposal-for-deep-resilience-responding-to-the-crisis-of-deep-uncertainty

Mekonnen, M. M. \& Hoekstra, A. Y. (2016). Four billion people facing severe water scarcity. Science Advances, 2(2), e1500323. DOI: 10.1126/sciadv.1500323

Remling, E. \& Causevic, A. (2021). Climate-related security risks in the 2020 updated Nationally Determined Contributions. SIPRI insights on peace and security, No. 2021/1. Solna: SIPRI. https://www.sipri.org/publications/2021/sipri-insights-peace-and-security/climate-relatedsecurity-risks-2020-updated-nationally-determined-contributions

Roidt, M. \& Avellán, T. (2019). Learning from integrated management approaches to implement the Nexus, Journal of Environmental Management, 237, 609-616. https://doi.org/10.1016/j.jenvman.2019.02.106.

Smith, D.M., Matthews, J.H., Bharati, L., Borgomeo, E., McCartney, M., Mauroner, A., Nicol, A., Rodriguez, D., Sadoff, C., Suhardiman, D., Timboe, I., Amarnath, G., \& Anisha, N. (2019). Adaptation's thirst: Accelerating the convergence of water and climate action. Background Paper prepared for the 2019 report of the Global Commission on Adaptation, Rotterdam and Washington, DC. http://www.iwmi.cgiar.org/Publications/Other/PDF/adapt ations-thirst-gca-background-paper.pdf

Timboe, I., Pharr, K., \& Matthews, J.H. (2020). Watering the NDCs: National Climate Planning for 2020-How water-aware climate policies can strengthen climate change mitigation \& adaptation goals. Corvallis, Oregon: Alliance for Global Water Adaptation (AGWA). https://www.wateringthendcs.org/ 
UN Climate Change. (2020). Climate Action Pathway: Water. Executive Summary. Marrakech Partnership for Global Climate Action. https://unfccc.int/documents/259188

UNESCO, UN-Water. (2020). United Nations World Water Development Report 2020: Water and Climate Change. Paris: UNESCO. https://unesdoc.unesco.org/ark:/48223/pf0000372985/ PDF/372985eng.pdf.multi

UN-Water. (2019). Climate Change and Water: UN-Water Policy Brief. UN-Water Expert Group on Water and Climate Change. https://www.unwater.org/publications/un-water-policy-briefon-climate-change-and-water/

WEF. (2021). The Global Risks Report 2021, 16th Edition, Geneva: World Economic Forum. http://www3.weforum.org/docs/WEF_The_Global_Risks_Report_2021.pdf

\section{Suggested citation}

Cooper, R. \& Price, R.A. (2021). Water Security and Climate Change. K4D Helpdesk Report 758. Brighton, UK: Institute of Development Studies. DOI: 10.19088/K4D.2021.116

\section{About this report}

This report is based on six days of desk-based research. The K4D research helpdesk provides rapid syntheses of a selection of recent relevant literature and international expert thinking in response to specific questions relating to international development. For any enquiries, contact helpdesk@k4d.info.

K4D services are provided by a consortium of leading organisations working in international development, led by the Institute of Development Studies (IDS), with Education Development Trust, Itad, University of Leeds Nuffield Centre for International Health and Development, Liverpool School of Tropical Medicine (LSTM), University of Birmingham International Development Department (IDD) and the University of Manchester Humanitarian and Conflict Response Institute (HCRI).

This report was prepared for the UK Government's Foreign, Commonwealth and Development Office (FCDO) and its partners in support of pro-poor programmes. Except where otherwise stated, it is licensed for non-commercial purposes under the terms of the Open Government Licence v3.0. K4D cannot be held responsible for errors, omissions or any consequences arising from the use of information contained in this report. Any views and opinions expressed do not necessarily reflect those of FCDO, K4D or any other contributing organisation.

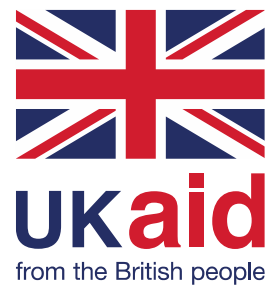

(C) Crown copyright 2021. 